\title{
Biomechanical Motion Analysis of Elite Flat Water Kayakers with Special Focus on Footrest
}

\author{
Bernadett Kertészné Német ${ }^{1 *}$, Tamás Terebessy¹, György Szőke ${ }^{1}$, Zoltán Bejek \\ ${ }^{1}$ Department of Orthopaedics - Semmelweis University, H- 1082 Üllői út 78/b, Budapest, Hungary \\ * Corresponding author, e-mail: nemet.bernadett@gmail.com
}

Received: 02 February 2021, Accepted: 02 March 2021, Published online: 10 March 2021

\begin{abstract}
The purpose of this study was to gain a better understanding of the importance of footrest use and the symmetry of kayaking motions. Method: Measurements were performed on 11 professional male Hungarian kayakers $(n=11)$, with a mean age of 24 years (range: 18-30 years), a mean height of 184, $5 \mathrm{~cm}$ (range: 172-197 cm), and a mean weight of $84 \mathrm{~kg}$ (72-96 kg). Weba sport kayak ergometer, Vicon MXT 3D camera system and surface electromyography were used for the measurements. The unique part of the study was the dynamometer, built into the footrest of the ergometer. The right and left sides differed significantly in terms of range of motion in the joints and activity of the muscles involved. Statistically significant differences were observed in the force applied to the footrest between the right and left sides. There were significant differences between the right and left stroke lengths in most athletes. There was a positive correlation between force applied to the footrest, the stroke length and the kayakers' power output. Our study identified differences and correlations between the parameters of kayaking motion, highlighting the importance of the footrest. Better and more precise footrest use allows correct technique to be applied with high performance.
\end{abstract}

Keywords

kayaking, kinematics, footrest

\section{Introduction}

Kayaking as an elite sport requires specialised technique and intense physical effort. In particular, kayak paddling requires symmetrical movements that provide forward propulsion [1-4]. Symmetrical and asymmetrical movements able to be act on the paddling and it may have an effect on the performance [5]. Previous studies have shown that the propulsion is most affected by the motion of the upper extremities and trunk. The lower extremities play a definitive role in power output in kayaking, which is numerically not clear in the scientific literature [6-9]. A few studies in the literature have drawn attention to motion analysis were observed in kayaking such as running and swimming [5].

There is a lack of numerical information in scientific literature about the utilization of the footrest during paddling. The goal of the present study was to gain more information about the footrest use, and the influence of that on the technique and power output. Obtaining more detailed information on muscle activities of elite male flat water kayakers can help improve individual training methods.
We performed a biomechanical study of the kayaking motions of elite flat water kayakers with a special focus on the force applied to the footrest on the left and right side of the athletes. We would determine the ranges of motion of the shoulder, elbow, trunk, and knee joints, as well as the activity of the muscles involved in kayaking motion.

Even if a kayaker's movements seem symmetrical, we thought in the ranges of motion of the major joints, the activities of the kayaker's dominant muscles and compression of the footrest may differ on the left side and right side. As a result of that we thought difference in the stroke length between right and left side too.

Accordingly, we hypothesized that there was a numerical connection between footrest use and power output and between the stroke length and power output. Quantitative characterisation of footrest use was the focus in our study, that help to determine numerically the correlation with the performance the latter of which is not clear in the scientific literature [5]. 


\section{Materials and methods}

Measurements were performed on 11 elite (leading sportsman) male Hungarian flat water kayakers with a mean age of 24 years (range: 18-30 years). Their mean biometrics were as follows: height, $184.5 \mathrm{~cm}$ (range: 172-197 cm); weight, $84 \mathrm{~kg}$ (range: $72-96 \mathrm{~kg}$ ). The study was conducted using a Weba sports kayak simulator, six Vicon MXT40 3-dimensional (3D) camera system (Vicon Motion System, $100 \mathrm{~Hz}$; Oxford Metrics, Oxford, UK), and surface electromyography (EMG) (FREEEMG; BTS Bioengineering, CE class IIa, FDA registration, UK).

\subsection{Examination process}

\subsubsection{Preparation}

The participants' anamnesis was taken, including the following anthropometric data of the lower extremities: distance from the anterior superior iliac spine to the tibial tuberosity, distance from the tibial tuberosity to the medial malleolus (length of the lower limb), distance between the medial and lateral tibial condyles (width of the knee), and distance between the medial and lateral malleolus (width of the ankle). In the upper extremities, the following measurements were taken: distance between acromion and axillary line (length of the upper limb), distance between medial and lateral humeral condyle (width of the elbow), distance between the styloid process of radius and the distal tip of the ulna (width of the wrist), and thickness of the middle third of the $3^{\text {rd }}$ metacarpal bone. These data were recorded on the right and left sides [9-11].

After recording these measurements in the Vicon system, we used two-sided tape to attach soft reflective markers with a neoprene base (Qualisys, SE) to the right and left anatomical points defined by the system.

Those were namely: the acromion, jugular incisure, distal third of the sternum, upper part of the humerus, lateral condyle of the humerus, upper part of the forearm, styloid process of the radius, distal end of the ulna, middle third of the $3^{\text {rd }}$ metacarpal bone, anterior superior iliac spine, posterior superior iliac spine, upper lateral third of the thigh, lateral femoral condyle, upper lateral part of the tibia, and lateral malleolus [12].

The 3D camera system used these markers and anthropometric data to detect the kayakers' body segments (Fig. 1). Following hair removal and skin disinfection, surface EMG electrodes were placed on the kayaker already positioned in the kayak simulator. Electrodes were placed on the following kayaking muscles on the right and left sides: the latissimus dorsi, medial deltoid, pectoralis major, brachial

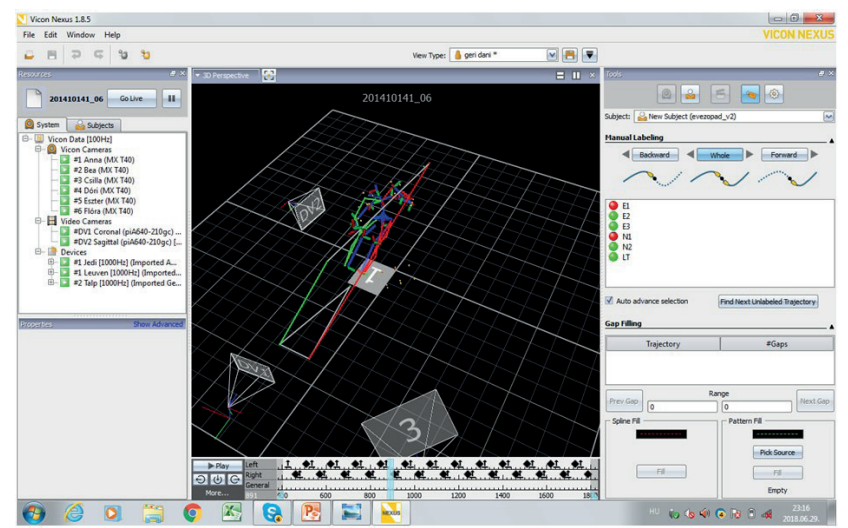

Fig. 1 Three-dimensional image of body segments during kayaking 200 metres. The red coloured is the left side, the green coloured is the right side. The blue points are determined the position of the trunk

biceps, rectus femoris, biceps femoris, and external oblique abdominal. The EMG signal lies in the frequency range from $0-500 \mathrm{~Hz}$ [13] In all cases, we checked the individual electrodes by asking the kayaker to use the tested muscle. Footrest also was checked with the maximal foot compression by the athletes.

Before static measurements with calibration, we start-up the system and the reference place was the laboratory. After calibration through static measurement were taken to identify and register the markers. The static part followed by the dynamical process.

\subsubsection{Measurement}

All the measured data were simultaneously streamed, synchronized and registered by a central computer [13-16]. The Vicon analysis has been made with 100 frame per second. The kayakers were directed to perform one active warm-up paddling under the supervision of the trainer and tracking by a heart-rate monitor (Polar H10), upon reaching $100 \%$ heart rate. All athletes' $100 \%$ heart rate data have been recorded in the central computer. The system uses this heart rate data to individually calculate sub maximal intensity $=$ maximal heart rate $\times 0.8$. The system used the simple method (maximal heart rate $\times 0.8=$ sub maximal intensity) to calculate the sub maximal intensity. After warm-up period and the calculation, athletes were directed to complete a 200 -metre course at $80 \%$ heart rate at sub-maximal intensity. This higher intermediate endurance testing method had been used in different biomechanical studies to analyse the performance in other elite sports [15-17]. These sub maximal data have been analysed through the investigation. After the test period athletes were allowed to active paddling cool down until their 
heart rate had returned to the appropriate range, which was also individually determined, and it was close to the rest heart rate. All measurements were taken under the supervision of a physician and a coach.

\subsection{Instruments}

Footrest use was measured using a dynamometer built into the footrest of the simulator, which was able to measuring the forces for the left and right foot separately.

The instrument measured the compression force applied to the footrest in Newton (Fig. 2 MEANWELL GS18A12-P1J, own photograph). The parts of the device: Dynamometer: 2 pieces dynamometer cell, 2 pieces footrest with foot strap, 1 piece basic sheet. Electronic part: power-supply, switch on bottom, switch on led, data cable, sensor. The parameters of the footrest dynamometer: Measurement limit: $1000 \mathrm{~N},(\sim 100 \mathrm{~kg})$, Maximal loadabilty: 2000 N, Maximal linear error: $<0.1 \%$, Pieso : $<0.4 \%$ /hour, repetition accuracy: $<1 \%$.

A foot strap was used to fix the foot onto the footrest in order to have a full contact between the footrest and the foot. The Weba sports kayak simulator was able to record and calculate information like, performance, stroke length, number of strokes and paddling distance. Such kayak ergometers are used for the so-called dry land trainings and even for competitions as well. These devices are the best tools to simulate conditions similar to water for the athletes [18].

The water and air phases of the stroke were determined by both the built-in system of the kayak simulator and the Vicon system, based on the onset and offset of the paddle in order to determine the stroke length. Stroke length is the length of the distance travelled by the shaft. The range of motion of the joint have been recorded through the three dimensional cameras and calculated by the Vicon system. Raw EMG data from each muscle were filtered. Root mean

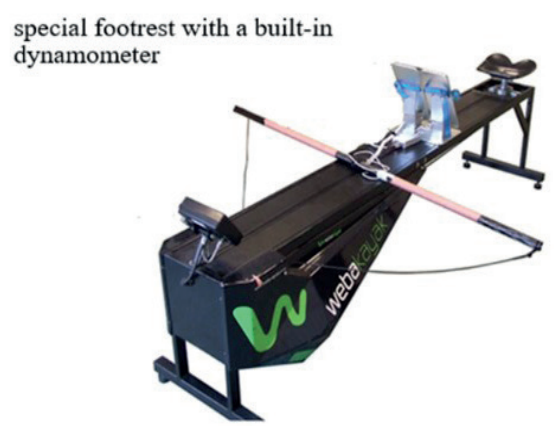

Fig. 2 Weba sports kayak simulator with built-in dynamometer to the footrest. This device is able to measure the force applied to the footrest (in Newton) during kayaking in real time both on the left and right side. (own photograph) square amplitudes were calculated using a 50-ms sliding window [2]. All data were collected and analysed in a central computer. Data as c3d files had been exported from the Vicon system to the Matlab system [1].

All the measured values were collected using Matlab (Version 8.3; The MathWorks Inc., USA) [6, 7]. Statistical analysis was performed using GraphPad Prism9. Wilcoxon tests and Pearson correlation were performed to statistically analyse the data.

\section{Results}

All the measured values were analysed, asymmetrical differences had been found between the right and left sides in terms of range of motion in joints, the trunk motion and the activity of the involved muscles as we hypothesized and it reached the level of significance in most cases (Figs. 3 and 4).

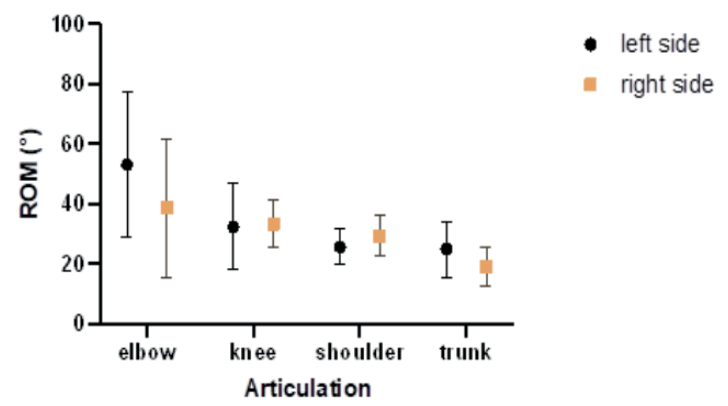

Fig. 3 Comparison of the range of motion of the joints on the left and right side across $200 \mathrm{~m}$ kayaking. All the measured values were analyzed, differences had been found between the right and left sides in terms of range of motion in joints and the trunk motion but that were not significant $\left(\mathrm{p}_{\text {elbow }}=0.2061 ; \mathrm{p}_{\text {knee }}=0.6377 ; \mathrm{p}_{\text {shoulder }}=0.4131 ; \mathrm{p}_{\text {trunk }}=0.1016\right)$

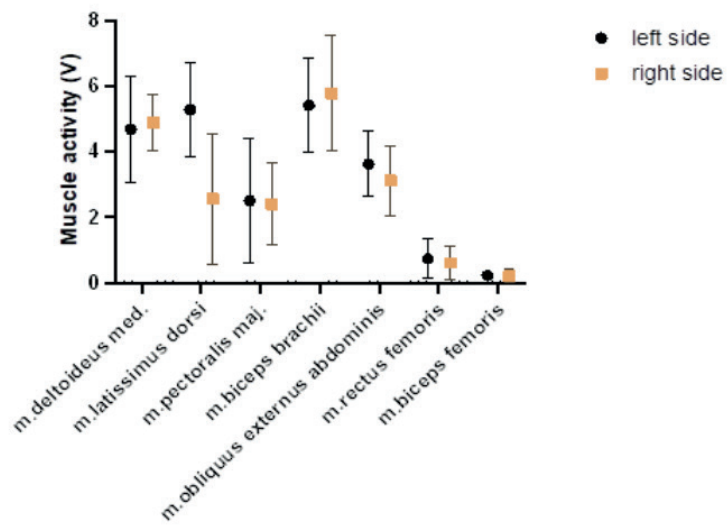

Fig. 4 Comparison of the muscle activity on the left and right side across $200 \mathrm{~m}$ kayaking. Differences had been found between the right and left sides in the activity of the involved muscles as we hypothesized, the differences were significant except by $\mathrm{m}$. deltiodeus and $\mathrm{m}$. pectoralis major. $\left(\mathrm{p}_{\text {latissimus }}<0.0001 ; \mathrm{p}_{\text {bic.brach. }}=0.0138 ; \mathrm{p}_{\text {obl. }}\right.$. ext $\left.<0.0001 ; p_{\text {rect.fem. }}=0.0369 ; p_{\text {bic.fem. }}=0.0449\right)$ 
The results on Fig. 4 represent the average of the maximum muscle activity. The most active muscles across 200 metre kayaking were the left musculus latissmus dorsi and the left and right $\mathrm{m}$. biceps brachii and $\mathrm{m}$. deltoideus. The average value of the musculus latissimus dorsi is $5.28 \mathrm{~V}(95 \% \mathrm{CI}: 4.97-5.60 \mathrm{~V})$ on the left side and $2.55 \mathrm{~V}$ (95\% CI: $2.12-3.00 \mathrm{~V}$ ) on the right side. The medialis part of the musculus deltoideus showed a high activity on both sides, with the mean of $4.89 \mathrm{~V}$ (95\% CI: 4.70-5.08 V) on the right side and the $4.68 \mathrm{~V}$ on the left side (95\% CI: $4.33-$ $5.04 \mathrm{~V})$. The musculus biceps brachii has a maximum of $6.84 \mathrm{~V}(95 \% \mathrm{CI}: 5.39-6.17 \mathrm{~V})$ on the right side and $6.90 \mathrm{~V}$ (95\% CI: $5.09-5.73 \mathrm{~V}$ ) on the left side. This muscle activity enables the flexion of the elbow joint during kayaking by an average of $38.79^{\circ}$ (95\% CI: $22.49-55.10^{\circ}$ ) on the right and $53.23^{\circ}\left(95 \% \mathrm{CI}: 36.27-70.18^{\circ}\right)$ on the left side. Furthermore, the maximum range of motion in the shoulder joint were $39.73^{\circ}$ (95\% CI: $24.65-34.17^{\circ}$ ) on the right side and $37.88^{\circ}\left(95 \% \mathrm{CI}: 21.68-29.94^{\circ}\right)$ on the left side. The less active muscles were the lower limb muscles: musculus rectus femoris with $0.61 \mathrm{~V}(95 \% \mathrm{CI}$ : $0.50-0.72 \mathrm{~V})$ average value on the right side and 0.72 V (95\% CI: 0.59 $0.86 \mathrm{~V}$ ) average value on the left side.

The average activity of the musculus biceps femoris was $0.20 \mathrm{~V}(95 \% \mathrm{CI}: 0.15-1.25 \mathrm{~V})$ on the right side and 0.23 (95\% CI: $0.21-0.25 \mathrm{~V}$ ) on the left side. In our study the knee flexion was an average of $33.39^{\circ}$ (95\% CI: $27.90-38.80^{\circ}$ ) on the right side, and $32.49^{\circ}$ (95\% CI: $\left.22.41-42.58^{\circ}\right)$ on the left side. As an effect of the alternating lower limb activity, there's an active trunk rotation of $19.17^{\circ}\left(95 \% \mathrm{CI}: 14.64-23.70^{\circ}\right)$ to the right and $25.03^{\circ}\left(95 \% \mathrm{CI}: 18.46-31.61^{\circ}\right)$ to the left and an intensive activity in musculus obliquus externus abdominis, $3.11 \mathrm{~V}(95 \% \mathrm{CI}: 2.88-3.34 \mathrm{~V})$ on the right side, $3.62 \mathrm{~V}$ (95\% CI: 3.40-3.84 V) on the left side have been observed during the measurement. This trunk and footrest activity allows the upper limb a more symmetrical cyclical motion. Differences were observed in the force applied to the footrest between the right and left sides, and they reached statistical significance in 9 out of 11 cases (Fig. 5). Significant differences in stroke length were observed between the right and left sides in most cases. (Fig. 6)

Additional analyses showed a very strong linear correlation between the force applied to the footrest and the kayaker's average stroke length, the Pearson correlation coefficient was 0.993. A moderate positive correlation was found between the force applied to the footrest and

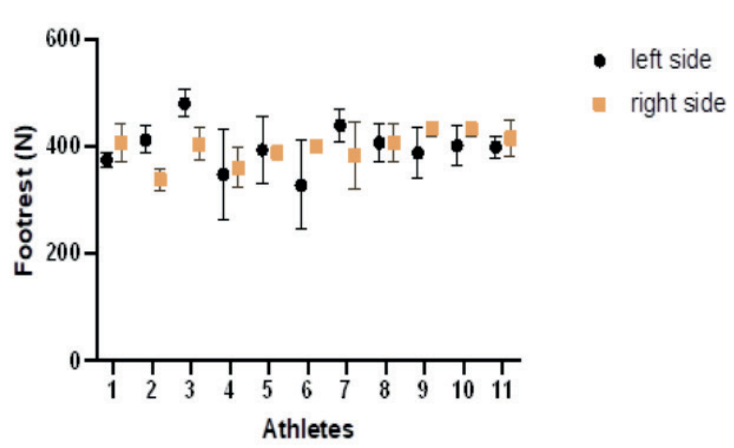

Fig. 5 Comparison of the footrest on the left and right side across 200 metre kayaking in case of elite male kayakers. Differences were observed in the force applied to the footrest on the right and left sides and it reached the level of statistical significance except in instances number 4 and $5 .\left(p_{2 ; 3 ; 6 ; 7 ; ; ; 10}<0.0001 ; p_{1}=0.0063 ; p_{8}=0.0156\right.$; $\left.\mathrm{p}_{11}=0.0225\right)$

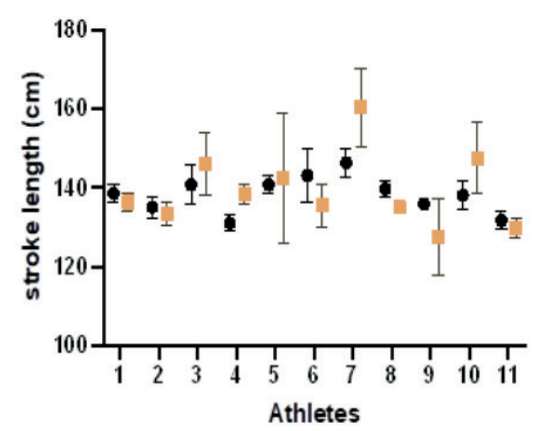

- left side

right side

Fig. 6 Stroke length comparison on the left and right side across 200 metre kayaking in case of elite male kayakers. Significant differences between the right and left sides were observed in all athletes except number 2 and 5. $\left(\mathrm{p}_{1}=0.0009 ; \mathrm{p}_{3}=0.0224 ; \mathrm{p}_{4}<0.0001 ; \mathrm{P}_{6}=0.0016\right.$; $\left.\mathrm{p}_{7}<0.0001 ; \mathrm{p}_{8}<0.0001 ; \mathrm{p}_{9}=0.0009 ; \mathrm{p}_{10}<0.0001 ; \mathrm{p}_{11}=0.0037\right)$

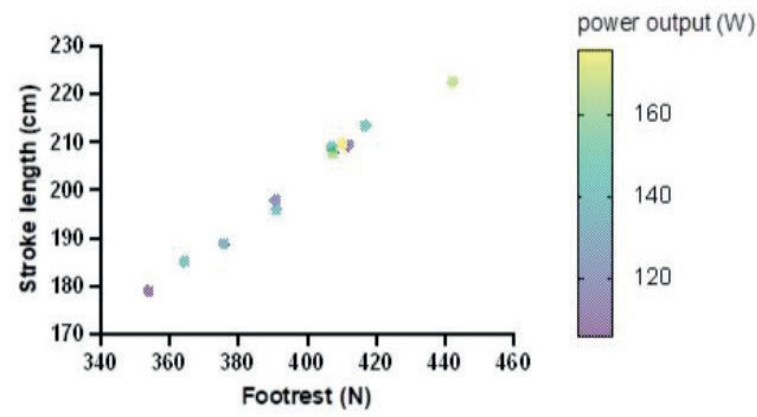

Fig. 7 Correlation of footrest, stroke length and power output with each other across 200 metre kayaking by professional male single kayakers. Pearson linear correlation coefficient between footrest and stroke length is 0.993 ; between footrest and power output 0.584 ; between stroke length and power output 0.591

the kayaker's power output, with a Pearson correlation coefficient of 0.584 . Correlation was also found between the stroke length and power output, with a coefficient of 0.591 (Fig. 7). 


\section{Conclusions}

Kayaking requires powerful and skilful paddling combined with appropriate technique to effectively maximize power and forward propulsion.

For sports that require symmetrical movement, any asymmetry in that, has a negative effect on power output. In the case of a kayak, a small degree of asymmetrical movement has a negative effect on the balance of the boat, it can deflect it from the straight line of movement. This should be continuously corrected by the athlete during paddling. Those continuous corrections require unnecessary energy consumption, which has a detrimental effect on power output.

The unique feature of our research was the locally designed and developed dynamometer built into the footrest, allowing footrest use to be quantified.

The study demonstrated in quantified form that significant and not significant asymmetry was observed during paddling. That is notable because both, significant and not significant asymmetry is a determining factor in power output.

The measurements demonstrated in a numerically visualised manner through the correlation coefficient that the power output is significantly assisted by the active, alternating work and symmetrical footrest support of the lower limbs. We also found a moderate correlation between the stroke length and the power output.

Power output is perhaps the most important factor in elite sports because the score of the athletes' depend on this factor. In the present study, great emphasis was placed on this factor, similar to most studies in the relevant scientific literature $[5,6]$. Considering that point our assessment emphasise that any kind of asymmetrical motions have an influence on the technique and the power output. In the opinion of the authors, in addition to using the tool during training, it may be suitable for reducing asymmetry, which can increase power output with good efficiency. The force awakened during the paddle movements of the upper limbs and the trunk acts on the boat through the footrest to make it move on the water. The footrest dynamometer developed during the research made the importance of this clear. It was possible to quantify the extent of this and observe an asymmetry between the left and right sides. Eliminating this asymmetry can also increase power output.

The measurements also provided numerical information on the range of motion of the joints and muscle activity involved in paddling. In the present study, these data were used to describe the asymmetric motion. After involving more athletes, analysis of these data may allow further conclusions to be drawn.

We are confident that the present study provided important and helpful information about successful kayak paddling. The use of kayak ergometer gave a wide range of circumstance for the assessment. We obtained new data to gain more information about athletes' kinematics of kayaking motions and muscle activities, and the connection of footrest use, stroke length and power output (time to perform a certain distance).

The system we used might provide significant support for a follow-up training process for the athletes and their coaches, according to the feedback received, proved to be a significant help in training planning and in preparing for competitions. The coach and the athlete are able to correct both, significant and not significant difference immediately. The visualization of the data also can help in direct proofing. The athlete can training through a control and later able to use the correct technique on water. Through the numerical follow up theoretical and technical refreshing is possible. Through the assessment a monitoring system had been created in order potentially correcting of minor differences. Our expectation is that the results of the present study will lead to more effective kayaking. Implications:

- Our results may serve as an important guidance during training. The system we used might provide significant support for a follow-up training process.

- A special dynamometer built into the footrest, allowing the quantification of footrest utilisation. Using this system could be more accurate (symmetrical) footrest use.

- The results of this study can provide more effective use of the footrest and lead to more effective kayaking.

\section{Acknowledgement}

This study has been obtained an ethical approval from the Ethics Committee of Hungary 14528-1/2019/EKU. The authors would like to express a great debt of attitude to the participants of the study. This research was performed in the biomechanical laboratory of the Orthopaedic Clinic of Semmelweis University. All figures and photographs in the manuscript are own.

\section{Conflicts of Interest}

The authors declare that they have no conflicts of interest. 


\section{References}

[1] López-Plaza, D., Alacid, F., Muyor, J. M., López-Miñarro, P. Á. "Differences in Anthropometry, Biological Age and Physical Fitness Between Young Elite Kayakers and Canoeists", Journal of Human Kinetics, 57, pp. 181-190, 2017. https://doi.org/10.1515/hukin-2017-0059

[2] Borne, R., Hausswirth, C., Costello, J. T., Bieuzen, F. "Lowfrequency electrical stimulation combined with a cooling vest improves recovery of elite kayakers following a simulated 1000-m race in a hot environment", Scandinavian Journal of Medicine \& Science in Sports, 25(S1), pp. 219-228, 2015.

https://doi.org/10.1111/sms.12392

[3] Murthag, M., Brooks, D., Sinclair, J., Atkins, S. "The lower body muscle activation of intermediate to experienced kayakers when navigating white water", European Journal of Sport Science, 16(8), pp. 1130-1136, 2016.

https://doi.org/10.1080/17461391.2016.1188993

[4] Nagymáté, G., Kiss, R. M. "Parameter Reduction in the Frequency Analysis of Center of Pressure in Stabilometry", Periodica Polytechnica Mechanical Engineering, 60(4), pp. 238-246, 2016. https://doi.org/10.3311/PPme.8999

[5] McDonnell, L. K., Hume, P. A., Nolte, V. "An observational model for biomechanical assessment of sprint kayaking technique", Sports Biomechanics, 11(4), pp. 507-523, 2012.

https://doi.org/10.1080/14763141.2012.724701

[6] Brown, M. B., Lauder, M., Dyson, R. "Activation and contribution of trunk and leg musculature to force production during on-water sprint kayak performance.", In: Proceedings of the 28th Conference of the International Society of Biomechanics in Sports, Marquette, MI, USA, 2010, pp. 203-206.

[7] Jáger, B., Jáger, D., Kristóf, T., Takács, M., Tamás, P., Kiss, R. M. "Validation of a Generally Applicable Method for the Characterization of Scoliotic Deformities and Sagittal Spinal Curvatures", Periodica Polytechnica Civil Engineering, 62(4), pp. 1021-1029, 2018.

[8] Michael, J. S., Rooney, K. B., Smith, R. M. "The dynamics of elite paddling on a kayak simulator", Journal of Sports Sciences, 30(7), pp. 661-668, 2012.

https://doi.org/10.1080/02640414.2012.655303

[9] Nilsson, J. E., Rosdahl, H. G. "Contribution of Leg-Muscle Forces to Paddle Force and Kayak Speed During Maximal-Effort FlatWater Paddling", International Journal of Sports Physiology and Performance, 11(1), pp. 22-27, 2016.

https://doi.org/10.1123/ijspp.2014-0030
[10] Hibbs, A. E., Thompson, K. G., French, D. N., Hodgson, D., Spears, I. R. "Peak and average rectified EMG measures: Which method of data reduction should be used for assessing core training exercises?", Journal of Electromyography and Kinesiology, 21(1), pp. 102-111, 2011. https://doi.org/10.1016/j.jelekin.2010.06.001

[11] Limonta, E. R., Squadrone, R., Rodano, R., Marzegan, A., Veicsteinas, A., Merati, G., Sacchi, M. "Tridimensional kinematic analysis on a kayaking simulator: key factors to successful performance", Sport Sciences for Health, 6(1), pp. 27-34, 2010. https://oi.org/10.1007/s11332-010-0093-7

[12] Vicon "Plug-in Gait Reference Gide" [online] Available at: https://usermanual.wiki/Document/Plugin20Gait20Reference20 Guide.754359891/view

[13] Hamacher, D., Krebs, T., Meyer, G., Zech, A. "Does local dynamic stability of kayak paddling technique affect the sports performance? A pilot study", European Journal of Sport Science, 18(4), pp. 491496, 2018. https://doi.org/10.1080/17461391.2018.1435726

[14] Kiss, R. M. "Verification of determining the spatial position of the lower extremity by ultrasound-based motion analyser", Periodica Polytechnica Civil Engineering, 51(1), pp. 39-43, 2007. https://doi.org/10.3311/pp.ci.2007-1.06

[15] Bishop, D. "Warm Up II - Performance Changes Following Active Warm Up and How to Structure the Warm Up", Sports Medicine, 33(7), pp. 483-498, 2003. https://doi.org/10.2165/00007256-200333070-00002

[16] Borges, T. O., Bullock, N., Duff, C., Coutts, A. J. "Methods for Quantifying Training in Sprint Kayak", Journal of Strength and Conditioning Research, 28(2), pp. 474-482, 2014. https://doi.org/10.1519/JSC.0b013e31829b56c4

[17] Begon, M., Colloud, F., Sardain, P. "Lower limb contribution in kayak performance: modelling, simulation and analysis", Multibody System Dynamics, 23, pp. 387-400, 2010. https://doi.org/10.1007/s11044-010-9189-8

[18] Fleming, N., Donne, B., Fletcher, D. "Effect of kayak ergometer elastic tension on upper limb EMG activity and 3D kinematics", Journal of Sports Science and Medicine, 11, pp. 430-437, 2012. https://www.jssm.org/jssm-11-430.xml\%3Eabst 